\title{
Canada stakes claim on fusion energy project
}

\section{Rex Dalton, San Diego}

Canada's bid to construct the Iter fusion energy research facility is building momentum, with moves to obtain governmental permits and support for the international collaborative project.

Iter Canada, a consortium that wants to build the multibillion dollar facility to study fusion as an energy source, started the environmental review process this week for a site at Clarington, near Toronto.

Backers of the project hope that Canadian prime minister Jean Chrétien may soon endorse Canada's project, which is competing against sites in Japan and France (see Nature 410, 856; 2001).

Iter, which originally stood for International Thermonuclear Experimental Reactor, is a joint effort between Japan, Europe and Russia to create an energy source by producing nuclear fusion in plasma confined magnetically in a doughnut-shaped chamber known as a tokamak.

The United States withdrew from the project in 1998, after Congress made large reductions in its fusion energy research programme. Canada's bid is seen as strategically significant, as it could potentially entice the United States back into the project. The costs would be borne by all the international participants.

Efforts are still under way in the United
States to boost fusion research funding. Representative Zoe Lofgren (Democrat, California), for example, is planning to introduce a bill that would revive US participation in Iter and inject a massive $\$ 320$ million into the project next year.

The Iter facility would conduct research intended to prove, in principle, that the tokamak could serve as a viable energy source. This device would burn plasma for a set period of time, although its specification has been cut back from an earlier one that was intended to ignite the plasma by making its burning self-sustained.

Formed three years ago, Iter Canada has

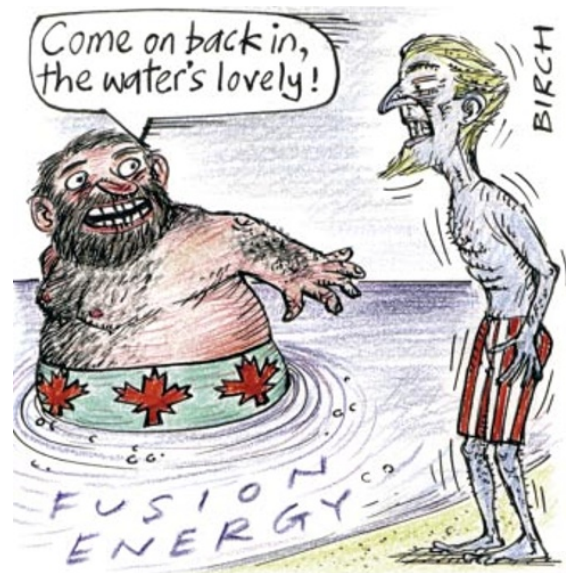

been garnering support for the fusion facility among Canadian businesses, labour groups and universities. The consortium recently incorporated the non-profit-making International Fusion Energy Institute, the body that filed for an environmental assessment of the fusion project by the Canadian Nuclear Safety Commission. This week, the commission's staff began preparing an environmental assessment of the project.

Iter Canada's chairman, Peter Barnard, noted that a host site must demonstrate that it can be licensed."We decided the best way to proceed is to get a licence," says Barnard, an engineer based in Toronto. After securing the appropriate environmental permit, Iter Canada faces a further government licensing process, which could take several years.

Iter Canada's proponents say support for their site is growing over the French and Japanese locations. Building the facility in Canada will be cheaper, they say, because the site is so well prepared and construction costs in the country are relatively low, leaving more funds for research.

The site at Clarington is near four nuclear reactors that produce tritium, Iter's fuel, as a by-product. Tritium is also an important component of nuclear weapons, and the requirement to handle it is seen as a potential impediment to Japan's bid to host Iter. http://itercanada.com

\section{Inquiry set up into Porton Down nerve-gas death}

\section{David Adam, London}

The British Ministry of Defence (MOD) is launching a new investigation into the circumstances surrounding the death of an airman who took part in military experiments with chemical warfare agents nearly 50 years ago.

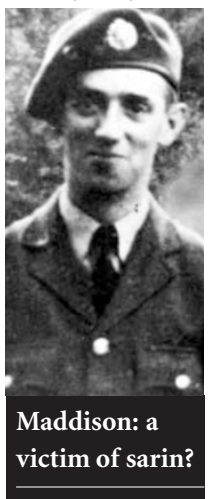

Ronald Maddison died in 1953, allegedly after the nerve agent sarin was dripped onto a patch of uniform taped to his arm in experiments aimed at establishing toxicity thresholds.

The MOD said on 1 May that it will carry out a 'historical survey' of its service volunteer programme, which ran from 1939 to 1989 at

Porton Down in Wiltshire. Formerly the site of controversial research on chemical and biological weapons, the centre remains active, working on defences against such weapons.
There have been claims that some volunteers were duped into taking part in nerve-gas trials, thinking they were helping to find a cure for the common cold. About 250 veterans who were involved in tests at Porton Down have formed a support group and have called on the MOD to investigate the possible health effects of the trials.

The review will be supervised by Ian Kennedy, a respected medical ethicist at University College London. An MOD spokesperson says it will cover "absolutely everything surrounding the programme who took part, how the volunteers were recruited, the way in which the programme was described to them and what they were told was taking place".

The announcement of the MOD review comes two months after the coroner, the local official responsible for enquiries into violent or accidental deaths, rejected the 1953 misadventure verdict returned on Maddison's death by an inquest held behind closed doors. That decision followed a twoyear police inquiry into events at Porton Down. The coroner's office is now awaiting a decision from the Attorney-General in London on a request to reopen the inquest, but does not expect a reply this year.

The MOD says its review is "not particularly related" to the coroner's desire to reopen the inquest, but that it is responding to public interest generated by the police inquiry. The reviewers will report next spring to the MOD, which says it will publish the findings.

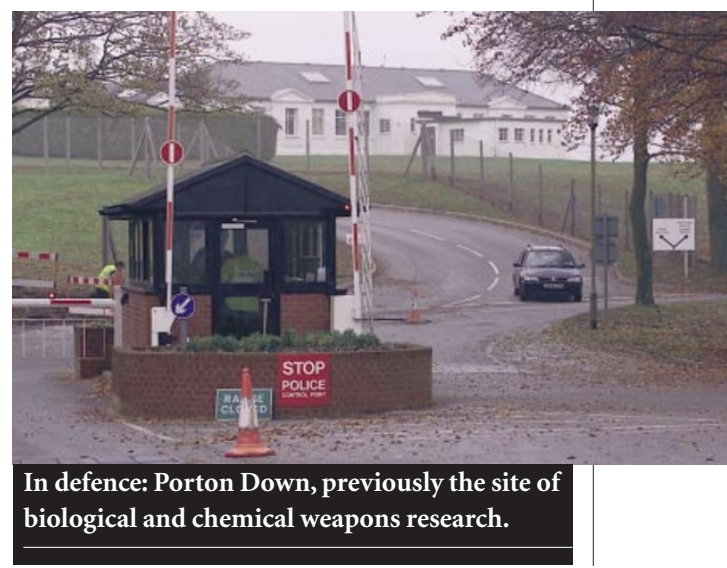

